\title{
Integrin-dependent Induction of Functional Urokinase Receptors in Primary T Lymphocytes
}

\author{
Elisabetta Bianchi, ${ }^{\star}$ Elisabetta Ferrero, ${ }^{\star}$ Francesca Fazioli, ${ }^{\ddagger}$ Francesca Mangili, ${ }^{\star}$ Jin Wang, ${ }^{\S}$ Jeffrey R. Bender, ${ }^{\S}$ \\ Francesco Blasi, ${ }^{\neq}$and Ruggero Pardi*\|ा \\ *Human Immunology and ${ }^{\ddagger}$ Molecular Genetics Units, Scientific Institute San Raffaele-DIBIT, I-20132 Milano, Italy; ${ }^{\S}$ Molecular \\ Cardiobiology, Boyer Center for Molecular Medicine, Cardiovascular Medicine, and the Raymond and Beverly Sackler Cardiobiology \\ Laboratory, Yale University School of Medicine, New Haven, Connecticut 06536-0812; Dipartimento di Genetica e Biologia dei \\ Microorganismi and ${ }^{\mathbb{I}}$ Dipartimento di Scienze e Tecnologie Biomediche, Università di Milano, I-20132 Milano, Italy
}

\begin{abstract}
In order to reach the sites of inflammation, lymphocytes leave the bloodstream and migrate into peripheral tissues, in a process involving integrin-mediated adhesion to the vascular endothelium, followed by transmigration across the endothelial barrier and through the underlying interstitial matrix. We have investigated the role of the plasminogen activator/plasmin system in normal $\mathrm{T}$ cell migration. Receptors for urokinase plasminogen activator (UPAR) were not expressed in resting $\mathrm{T}$ lymphocytes, but could be efficiently induced at the mRNA and protein level by coclustering of the antigen receptor complex and $\beta 1$ or $\beta 2$ integrins, through a signalling pathway involving both protein kinase $\mathrm{C}$ activation and an increase in intracellular cyclic AMP. Catalytic activation of plasminogen by uPAR-expressing $T$ cells promoted their migration through an extracellular matrix in vitro. Plasmin-induced invasion was inhibited by plasmin-and urokinase inhibitors and by anti-uPAR antibodies. Finally, cytofluorimetric and immunohistochemical analysis of primary human tumor specimens showed the presence of $\mathrm{UPAR}$ positive infiltrating $\mathrm{T}$ cells in vivo. Collectively, these findings suggest that plasminogen activation may play a role in lymphocyte migration in vivo, and that integrin-dependent expression of membrane-associated endopeptidases could represent an additional step in the regulated process of leukocyte transmigration. (J. Clin. Invest. 1996. 98:1133-1141.) Key words: plasminogen activators • cell adhesion molecules $\bullet$ cell movement $\bullet$ neoplasms $\bullet$ cyclic AMP
\end{abstract}

\section{Introduction}

Extravasation and migration into inflammatory or neoplastic foci in peripheral tissues are instrumental to the ability of $\mathrm{T}$ lymphocytes to perform antigen-specific effector functions. Transendothelial migration of lymphocytes is currently viewed as a step-wise process that involves initial, selectin-mediated

Address correspondence to Ruggero Pardi, M.D., Unit of Human Immunology, Scientific Institute San Raffaele-DIBIT, via Olgettina, 58, I-20132 Milano, Italy. Phone: 2-2643-4731; FAX: 2-2643-4723; E-mail: pardir@dibit.hsr.it

Received for publication 3 April 1996 and accepted in revised form 24 June 1996.

J. Clin. Invest.

(C) The American Society for Clinical Investigation, Inc. 0021-9738/96/09/1133/09 \$2.00

Volume 98, Number 5, September 1996, 1133-1141 rolling along the luminal side of postcapillary venules, followed by integrin-mediated firm adhesion to the endothelium and, finally, chemokine-driven transmigration across the endothelial cell monolayer $(1,2)$. Integrin engagement is dependent on prior activation of the T cell, which causes a shift in the avidity of the integrins for their ligands (3). Transmigrated lymphocytes need to interact dynamically with the extracellular matrix in order to reach their final destination, but how this process is regulated at the molecular level has not yet been defined. The plasminogen activation system has been shown to play a prominent role in many physiological and pathological processes involving cell migration and infiltration in the surrounding tissues which require the remodelling of the extracellular matrix, such as trophoblast implantation, angiogenesis, wound healing and tumor invasion (4-6, and references therein). Urokinase-type plasminogen activator (uPA $)^{1}$ converts plasminogen to the active form plasmin, a serine protease with broad specificity, which activates a cascade of proteolytic events, leading to fibronectin, laminin, and collagen degradation. Receptors for urokinase (UPAR) localize uPA at the cell surface (7-9). Binding of UPA to its receptor, not only increases the rate of enzymatic activation of plasmin, but also makes cell-associated proteolysis a focal and spatially oriented process, which may be more functional to cell migration (10). UPAR has been identified as the monocyte activation antigen Mo-3 (11) and is expressed in addition by several unstimulated, circulating haematopoietic cells, such as granulocytes and natural killer cells, as well as by in vitro activated T cells (12-14). However, the functional significance of plasminogen activation for $\mathrm{T}$ cell function has not been investigated. In this work we asked whether uPAR could be induced in normal $\mathrm{T}$ cells by physiological stimuli associated with the activation/transmigration process and whether UPAR expression was functionally important for $\mathrm{T}$ cell migration. Co-clustering of the antigen receptor complex and $\beta 1$ or $\beta 2$ integrins by the use of specific mAbs was found to be one of the most efficient stimuli for uPAR membrane expression. The analysis of the second messengers involved in integrin-dependent expression of uPAR pointed to a major contribution, together with protein kinase $\mathrm{C}$ (PKC) activation, of a cAMP-dependent pathway, as co-clustering of the activation and adhesion receptors induced persistent elevation of $[\mathrm{cAMP}]_{\mathrm{i}}$ and $\mathrm{uPAR}$ expression under these conditions could be abrogated by selective adenylyl cyclase inhibitors. uPAR expressing $\mathrm{T}$ cells utilized the receptor to actively in-

1. Abbreviations used in this paper: AC, adenylyl cyclase; BIM, bisindolylmaleimide; DAG, diacylglycerol; EACA, epsilon-aminocaproic acid; FSK, forskolin; PI, phosphatidylinositol; PKC, protein kinase C; TIL, tumor infiltrating lymphocytes; uPA, urokinase-type plasminogen activator; $\mathrm{uPAR}$, receptors for urokinase. 
vade matrigel-based matrices in vitro, when the appropriate cofactors were provided. Finally, cytofluorimetric and immunohistochemical analysis of human tumor specimens characterized by the presence of infiltrating $\mathrm{T}$ lymphocytes indicated that UPAR expression by $\mathrm{T}$ lymphocytes occurs also in vivo.

\section{Methods}

Chemicals and antibodies. PMA, forskolin, epsilon-aminocaproic acid (EACA), amiloride, plasmin-free plasminogen, collagenase, jaluronidase, DNAse, and BSA were obtained from Sigma Immunochemicals (St. Louis, MO). Aprotinin was purchased from Bayer (Trasylol, Zurich, Switzerland). The protein kinase C inhibitor bisindolylmaleimide (BIM) was purchased from Boehringer Mannheim (Mannheim, Germany). The adenylyl cyclase inhibitor SQ 22536 (9[tetrahydro-2-furyl]adenine) was from Calbiochem (Lucerne, Switzerland). Anti-CD3 $\epsilon$-chain $\mathrm{mAb}$ OKT3 $\left(\mathrm{IgG}_{2 \mathrm{a}}\right)$ and anti-CD14 mAb $3 \mathrm{C} 10\left(\mathrm{IgG}_{2 \mathrm{~b}}\right)$ were purchased from American Type Culture Collection (Rockville, MD); anti-CD25 mAb was from Beckton Dickinson \& Co. (San Jose, CA); anti-CD49d (anti- $\alpha 4)$, anti-CD49f (anti- $\alpha 5)$, and anti-CD29 (anti- $\beta 1$ ) were from Amac, Inc. (Westbrook, ME), anti-CD11a $(\alpha \mathrm{L})$ mAb $2 \mathrm{~F} 12\left(\mathrm{IgG}_{1}\right)$ was kindly provided by $\mathrm{R}$. Schmidt (Hannover Medical School, Hannover, FRG); anti-CD18 $(\beta 2)$ mAb TS1.18 $\left(\operatorname{IgG}_{1}\right)$ was kindly provided by T.A. Springer (Harvard Medical School, Boston, MA); anti-CD16 mAb KD1 ( $\left.\operatorname{IgG}_{1}\right)$ was a gift of A. Poggi (Istituto Nazionale Tumori, Genova, Italy). The irrelevant control mouse myeloma IgG1k (MOPC 21) was from Sigma Immunochemicals. Affinity purified, polyclonal goat anti-mouse IgG (GAM-IgG, heavy and light chain-specific) and FITC-conjugated goat anti-mouse IgG were purchased from Zymed (S. San Francisco, CA). FITC-labeled Swine anti-rabbit IgG was obtained from Dako (Copenhagen, Denmark). Rhodamine (TRITC)-conjugated polyclonal goat anti-mouse $\mathrm{IgG}$, human adsorbed, and goat anti-mouse kappa light chain, human adsorbed, were from Southern Biotechnologies Assoc. Inc. (Birmingham, AL). The anti-uPAR rabbit polyclonal has been previously described (15). The anti-uPAR mouse monoclonals (R2, R3, and R4) were kindly provided by E. Rønne and G. Høyer-Hansen (Finsen Laboratory, Copenhagen, Denmark) (16).

Cell isolation and cultures. T lymphocytes were purified from buffy coats obtained from the San Raffaele Hospital Blood Center (Milan, Italy). PBMC were isolated by density gradient centrifugation on Ficoll Hypaque (Nycomed Pharma AS, Oslo, Norway). Monocytes were depleted by two rounds of plastic adherence for $1 \mathrm{~h}$ at $37^{\circ} \mathrm{C}$ followed by a passage on nylon wool columns at $37^{\circ} \mathrm{C}$. NK cells and residual mielomonocytic cells were removed by negative selection with anti-CD16 and anti-CD14 mAbs using a panning method (17). The resulting population of cells was more than $95 \% \mathrm{CD}^{+}$by flow cytometry. T cells were activated with either anti-CD3 antibodies $\left(0.1 \mu \mathrm{g} / 10^{6}\right.$ cells) alone or with anti-CD3 plus anti- $\alpha \mathrm{L}$ and anti- $\beta 2$ antibodies $(0.1$ $\mu \mathrm{g} / 10^{6}$ cells) for simultaneous clustering of the LFA- 1 integrin: cells were incubated with the antibodies 20 min on ice, excess antibody was washed out, and cells were plated in complete medium (RPMI, 10\% FCS) on goat anti-mouse IgG-coated plates, for the indicated times. In some experiments, cells were treated with anti-CD3 and goat antimouse IgG antibodies, followed by removal of excess antibody and plating onto anti-LFA-1-coated dishes. For stimulation through the VLA- 4 and VLA-5 integrin receptors, a combination of anti- $\alpha 4$ and anti- $\beta 1$, or of anti- $\alpha 5$ and anti- $\beta 1$, was respectively used $(0.1 \mu \mathrm{g} / \mathrm{ml})$. In some experiments, cells were plated in complete medium in the presence of the indicated combinations of PMA $(100 \mathrm{nM})$, forskolin $(20$ $\mu \mathrm{M})$, SQ $22536(100 \mu \mathrm{M})$, and BIM $(1 \mu \mathrm{M})$. The two latter compounds were added to the cultures every $24 \mathrm{~h}$. Tumor infiltrating lymphocytes (TIL) were isolated from three human tumor surgical specimens, obtained from the Surgery Department of the San Raffaele Hospital. Tumor tissues were enzyme digested $(10 \%$ collagenase [wt $/ \mathrm{vol}], 1 \%$ jaluronidase, $0.2 \%$ DNAse), after several washes in phosphate buffer, TIL were separated from tumor cells by Ficoll-Hypaque density gradi- ent. The recovered cell population was immediately analyzed for cell surface phenotype and uPAR expression.

Cytofluorimetric analysis of cell surface phenotype. Cells were washed with $1 \%$ PBS, $0.1 \%$ FCS, $\mathrm{NaN}_{3}$, and membrane-stained with antiuPAR mAb $(5 \mu \mathrm{g} / \mathrm{ml})$ or with CD $25 \mathrm{mAb}(2 \mu \mathrm{g} / \mathrm{ml})$ for $20 \mathrm{~min}$ on ice. After washing, cells were incubated with a FITC-conjugated goat anti-mouse IgG polyclonal antibody. In experiments where $\mathrm{T}$ cells were stimulated with anti-CD3 or anti-LFA-1 mAb, cells were stained with a rabbit polyclonal Ab anti-uPAR (1:40), followed by a FITC-conjugated goat anti-rabbit polyclonal. Fluorescence was measured with FACScan ${ }^{\circledR}$, Becton Dickinson \& Co.). As negative control, an isotype-matched irrelevant $\mathrm{Ab}$ (MOPC1), or preimmune rabbit serum were used.

uPAR binding assay. Purified primary $\mathrm{T}$ lymphocytes were incubated in serum-free binding buffer $(50 \mathrm{mM}$ Hepes, $\mathrm{pH} 7.4,50 \mathrm{mg} / \mathrm{ml}$ bovine serum albumin), acid washed to eliminate any receptor-bound endogenous uPA, and resuspended in the cold in binding buffer (18). One million cells in $0.2 \mathrm{ml}$ were incubated at $0^{\circ} \mathrm{C}$ with increasing amounts of iodinated ATF, the amino terminal fragment of uPA which contains the uPAR binding site, and binding was measured as described before (18). Each sample was run in triplicate, with or without a 100 -fold excess unlabeled pro-uPA. Non-specific binding never exceeded $5 \%$ of the bound ATF. ${ }^{125}$ I-ATF was iodinated to a specific activity of $12,300 \mathrm{cpm} / \mathrm{ng}$.

Northern blot analysis. Total RNA was extracted from resting and activated T cells with the RNAzol B kit (Biotecx Lab., Houston, TX) following manufacturer's instruction. $15 \mu \mathrm{g}$ of total RNA were run on $1.5 \%$ denaturing agarose gels and blotted on positively charged membranes (Hybond $\mathrm{N}^{+}$; Amersham, Buckinghamshire, UK) by capillary transfer. Probes (uPAR full length cDNA) were labeled with ${ }^{32} \mathrm{P}$-dCTP, with the Megaprime labeling kit (Amersham). Hybridizations of filters were performed at $65^{\circ} \mathrm{C}$ in $125 \mathrm{mM}$ sodium phosphate (pH 7.2), $250 \mathrm{mM} \mathrm{NaCl}, 7 \%$ SDS, $10 \%$ PEG. Filters were washed at $65^{\circ} \mathrm{C}$ to final stringency of $0.2 \times$ SSC for 20-30 min. Hybridized membranes were exposed to Kodak XAR films (Eastman Kodak, Rochester, NY) and the films analyzed with a Computing Densitometer (Molecular Dynamics, Sunnyvale, CA). As a control for monocyte contamination, membranes were hybridized with a CD14 probe (kind gift of Donata Vercelli, DIBIT, MI, Italy). Total RNA $(4 \mu \mathrm{g})$ obtained from a monocytic cell line (THP1) was loaded as a positive control.

Matrigel invasion assay. The ability of activated T lymphocytes to traverse a basement membrane substrate in vitro was assayed using a Matrigel-coated (Collaborative Research Biomedical Products, Bedford, MA) semi-porous membrane. Briefly, Transwell chambers (Costar, Cambridge, MA) containing filters with $5 \mu \mathrm{m}$ pores were coated with $40 \mu \mathrm{l}$ Matrigel (1:1 vol/vol dilution in cold serum-free medium) and incubated at $37^{\circ} \mathrm{C}$ for $60 \mathrm{~min}$ to allow gelling of the matrix. T lymphocytes were activated for $72 \mathrm{~h}$ by cross-linking of the CD3 and LFA-1 receptors to induce expression of uPAR. Activated cells, labeled with ${ }^{51} \mathrm{Cr}\left(10 \mu \mathrm{Ci} / 10^{6}\right.$ cells $)$ were resuspended in RPMI $1 \%$ Nutridoma (Boehringer, Mannheim, Germany), added to the Transwell chambers $\left(2 \times 10^{5}\right.$ cells/well $)$ and incubated at $37^{\circ} \mathrm{C}$ overnight, in the presence or absence of urokinase (final concentration $0.05 \mathrm{nM}$ ) and/or plasminogen (final concentration, $100 \mu \mathrm{M}$ ). After this period, migrated cells were recovered from the bottom chamber and from the Matrigel layer, after extensive washing with an EDTA-containing buffer to remove loosely attached cells. The recovered cells were lysed and cell-associated radioactivity counted in a gamma counter (Packard Instruments, Downers Grove, IL). In a set of experiments, the following reagents were added to the upper well at the start of the culture period: aprotinin $(100 \mu \mathrm{g} / \mathrm{ml})$, epsilon-aminocaproic acid $(30 \mu \mathrm{M})$, amiloride $(0.1$ $\mathrm{mM}$ ), antibodies against uPAR (mAb R2, mAbR3 $10 \mu \mathrm{g} / \mathrm{ml}$ ), or isotype-matched irrelevant antibodies (MOPC21, $10 \mu \mathrm{g} / \mathrm{ml}$ ).

Immunohistochemistry. $4 \mu \mathrm{m}$ cryostat sections of human breast, pancreatic, and lung tumors were fixed in acetone/chloroform, $5 \mathrm{~min}$ at $4^{\circ} \mathrm{C}$, and immediately air-dried. Sections were incubated several hours at $4^{\circ} \mathrm{C}$ in PBS with $0.1 \%$ Tween (PBT) and $5 \%$ BSA. Sections 

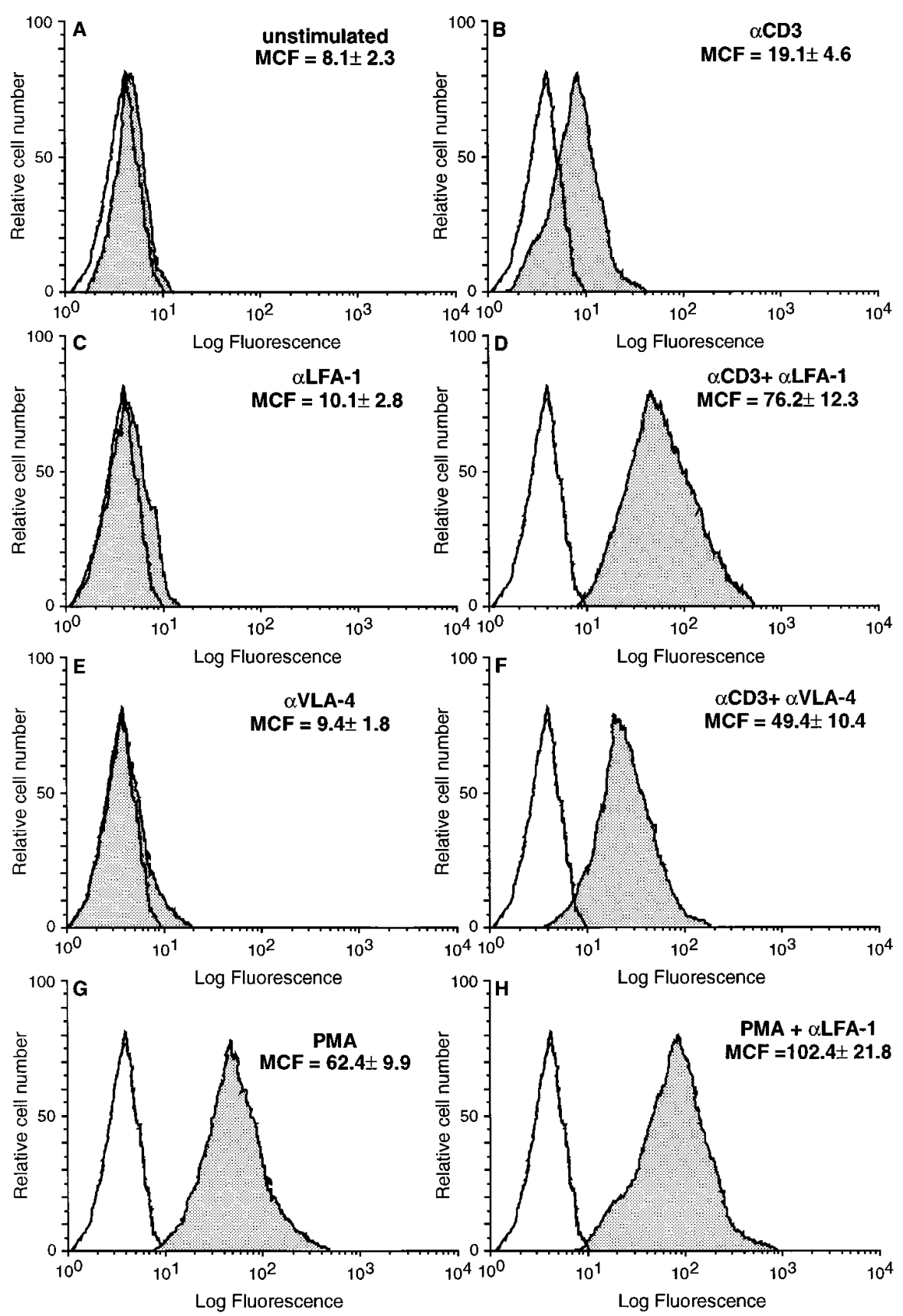

Figure 1. Cell surface expression of urokinase receptors (u-PAR) in resting and activated T lymphocytes. Purified T cells ( $>95 \%$ ) were isolated from peripheral blood and stimulated for $72 \mathrm{~h}$ by cross-linking the $\mathrm{T}$ cell antigen receptor complex (CD3) and/or the integrin receptors of the $\beta 2$ (LFA-1) or the $\beta 1$ (VLA-4) families with specific antibodies (anti- $\beta 2+$ anti- $\alpha \mathrm{L}$ for LFA1, and anti- $\beta 1+$ anti- $\alpha 4$ for VLA- 4 ) as described in Methods. As a positive control, cells were activated with PMA (100 nM). Cells were stained by indirect immunofluorescence with a polyclonal antibody against u-PAR (shaded diagrams) and analyzed on a FACScan ${ }^{\circledR}$. Results from a representative experiment are shown. (Clear diagrams) Cells labeled with pre-immune rabbit serum. (MCF) Mean channel fluorescence, expressed as log arbitrary units.

from eight different tumor samples were analyzed. The sections were blocked $20 \mathrm{~min}$ at room temperature (RT) in PBS $20 \%$ normal swine serum, followed by an anti-human CD3 polyclonal Ab (1:100 in PBT, $5 \%$ BSA). Sections were washed three times in PBT at RT and incubated with the secondary Ab (FITC-swine anti-rabbit polyclonal, 1:25) for $30 \mathrm{~min}$ at RT. After extensive washing, sections were blocked for 20 min at RT in PBS with $10 \%$ normal goat serum, followed by 60 min at RT with the anti-uPAR mAb R2 and R4 (5 $\mu \mathrm{g} / \mathrm{ml}$ each). Sections were washed three times in PBT and incubated $30 \mathrm{~min}$ at RT with the TRITC-conjugated anti-IgG1 and anti-kappa chain antibodies (1:100). After washing in PBT, sections were mounted in $50 \%$ glycerol and examined under a Zeiss microscope (Jena, Germany).

\section{Results}

UPAR expression on activated lymphocytes. Highly enriched T cells $\left(>95 \% \mathrm{CD}^{+}\right)$were isolated from the peripheral blood of healthy donors. Unstimulated T cells were negative for surface UPAR expression for several days after isolation, as shown by $\mathrm{FACS}^{\circledR}$ analysis (Fig. $1 A$ ). Immobilized monoclonal antibodies were used to mimic natural ligands, to explore the role of different cell surface receptors in the induction of uPAR. Cross-linking of the antigen receptor with anti-CD3 antibody induced low but detectable levels of uPAR on a large fraction of the population (Fig. $1 \mathrm{~B}$ ). While ligation of the LFA-1 receptor alone had no effect on UPAR induction at any of the time-points examined (Fig. $1 C$ ), simultaneous clustering of the CD3 receptor with the integrin receptor LFA-1 had a consistent synergistic effect in inducing uPAR homogeneously throughout the T cell population (Fig. $1 D$ ). uPAR expression steadily increased with time and reached a plateau at 48 to $72 \mathrm{~h}$ following the initial stimulus (Fig. 2). Similar results were obtained using immobilized anti-LFA-1 antibody combined to 


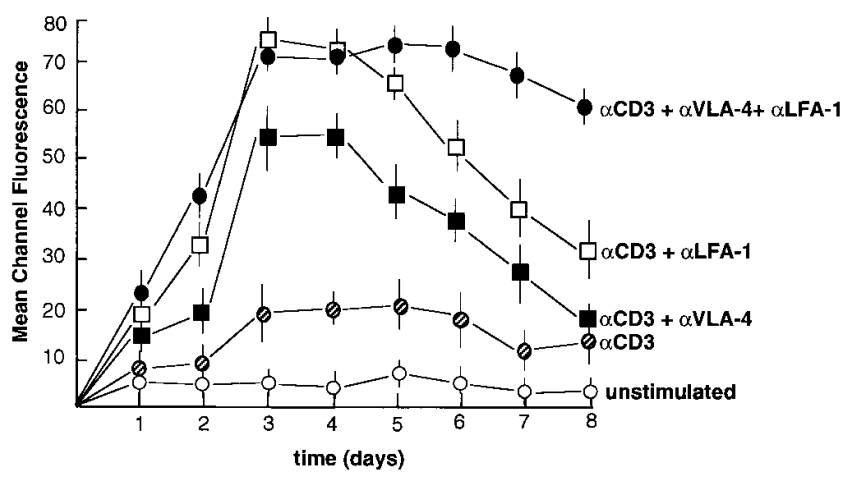

Figure 2. Time-course analysis of u-PAR expression on stimulated T lymphocytes. Purified T cells were stimulated by cross-linking different cell surface receptors with the indicated combination of antibodies and samples were collected at the indicated time points and analyzed for u-PAR surface expression by indirect immunofluorescence, as indicated in Fig. 1. Intensity of $\mathrm{u}-\mathrm{PAR}$ expression is indicated as mean channel fluorescence values, and represents the mean \pm SD of eight separate experiments.

soluble anti-CD3 antibody (not shown), suggesting that antibody-mediated co-capping of the two receptors is not strictly required for the synergistic induction of UPAR expression. Antibodies directed against integrins of the $\beta 1$ family, such as VLA-4 and VLA-5, cooperated with anti-CD3 in stimulating uPAR expression (Fig. $1 F$, Fig. 2 and data not shown), although less efficiently than antibodies to LFA-1. Interestingly, simultaneous cross-linking of LFA-1 and VLA-4 with the CD3 complex did not further increase the overall surface density of uPAR, but resulted in long-term persistence $(>8 \mathrm{~d})$ of its expression in T cells (Fig. 2).

The increase in functional uPAR in anti-CD3 plus antiLFA-1 stimulated T cells was also tested by direct binding experiments with iodinated ATF, the amino-terminal fragment of UPA deprived of protease activity but including the functional uPAR-binding site (18). Comparison of unstimulated and antibody-stimulated cells, at the peak of surface uPAR expression, showed that the number of ATF-binding sites was increased more than 10-fold (Fig. 3). Analysis of the data indicated that the induced receptors display high affinity, with
$50 \%$ occupancy in stimulated lymphocytes obtained at $2 \mathrm{nM}$ ATF, comparable to that previously reported in many other cell lines (19). Scatchard analysis confirmed these data (not shown).

Second messengers involved in the co-stimulatory activity of $\beta 2$ integrins. Signaling through the T cell antigen receptor complex results in the activation of the phosphatidylinositol (PI) pathway, which leads to generation of diacylglycerol (DAG) and protein kinase $\mathrm{C}$ activation $(20,21)$. Clustering of LFA-1 has also been reported to be an efficient stimulus for PI hydrolysis and DAG generation $(22,23)$. The importance of this pathway in the induction of UPAR in our model was shown by the fact that phorbol esters (PMA, $100 \mathrm{nM}$ ), as previously reported (14), were sufficient to induce T cell surface uPAR expression (Figs. $1 G$ and 4). This effect was completely blocked by treatment with the selective PKC inhibitor BIM (Fig. 4). Addition of BIM also blocked uPAR expression induced by simultaneous cross-linking of CD3 and LFA-1, indicating a role for PKC activation in this pathway of uPAR induction. Cross-linking of LFA-1 synergized with PMA in stimulating UPAR expression, suggesting the existence of a complementary activation pathway (Fig. 1).

We have previously reported that simultaneous clustering of the CD3 and the LFA-1 receptors induces also a gradual and persistent elevation of the intracellular concentration of cAMP (24). We have therefore studied the role of the increased cAMP concentration in the induction of UPAR, by stimulating UPAR expression in the presence of the specific adenylyl cyclase (AC) inhibitor SQ22536 $(100 \mu \mathrm{M})$. Under these conditions, the effect of anti-CD3 alone on UPAR stimulation was abolished and that of anti-CD3 plus anti-LFA-1 mAbs strongly reduced (Fig. 4). In the latter case, the further addition of BIM decreased uPAR expression to background levels (not shown). Activation of $\mathrm{AC}$ alone was inefficient in stimulating uPAR expression, as treatment of $\mathrm{T}$ cells with forskolin (FSK), which directly activates AC, did not induce significant expression of UPAR (not shown). FSK had an additive effect on UPAR induction by PMA treatment; addition of SQ22536, to block adenylyl cyclase activation by FSK, reduced UPAR expression to levels seen with PMA treatment alone, pointing to the fact that the two pathways of induction may be, at least in part, independent (Fig. 4). The inhibitor SQ22536 had no effect on uPAR induction by PMA (Fig. 4).

$u P A R$ expression is modulated at the $m R N A$ level. To test

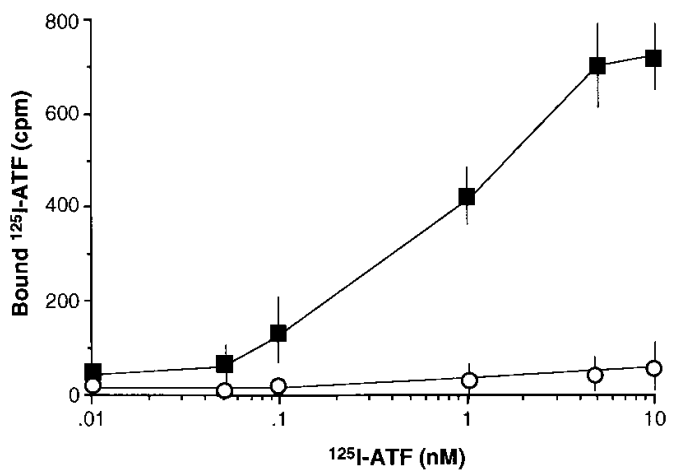

Figure 3. ${ }^{125}$ I-labeled ATF binding by primary T lymphocytes. Freshly isolated, purified T lymphocytes, either unstimulated $(\bigcirc)$ or stimulated by simultaneous clustering of the CD3 and LFA-1 receptors $\left(48 \mathrm{~h}\right.$ at $\left.37^{\circ} \mathrm{C}, \boldsymbol{\square}\right)$, were exposed to the indicated concentrations of ${ }^{125}$ I-labeled ATF as described in the Methods section. Binding is expressed in counts per minute (cpm), and represents the mean \pm SD of triplicate samples.

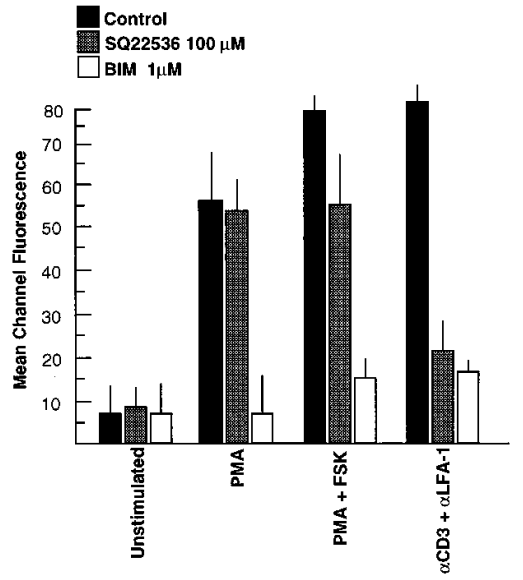

Figure 4. Analysis of second messengers involved in u-PAR induction. T cells were stimulated for $72 \mathrm{~h}$ with either PMA alone (100 nM), PMA and forskolin (20 $\mu \mathrm{M}$ ), or with a combination of anti-CD3 and anti-LFA1 antibodies, in the absence (black bars) or in the presence of an inhibitor of adenylyl cyclase (SQ22536, $100 \mu \mathrm{M}$, hatched bars) or of an inhibitor of Protein Kinase C (BIM, 1 $\mu \mathrm{M}$, empty bars). Sam-

ples were analyzed for u-PAR expression by indirect immunofluorescence. Mean values of u-PAR expression from three independent experiments are indicated as $\mathrm{MCF} \pm \mathrm{SD}$. 
A

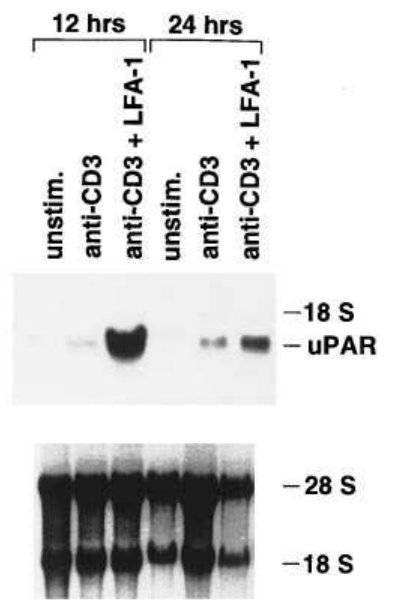

B

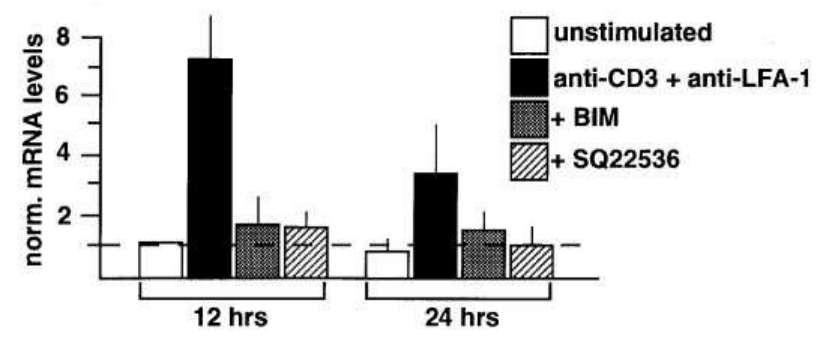

Figure 5. u-PAR mRNA expression in resting and activated T lymphocytes. $(A)$ Total RNA was extracted from unstimulated T cells and from cells stimulated with anti-CD3 Ab alone or in combination with anti-LFA $1 \mathrm{Ab}$ for the indicated times. $15 \mu \mathrm{g}$ of RNA were run on a denaturing gel, blotted, and probed for u-PAR expression (top). (Bottom) Ethidium bromide staining of RNA gel. (B) Total RNA was obtained from unstimulated T cells (white bars), cells stimulated by cross-linking of CD3 and LFA1 receptors (black bars), and cells stimulated by cross-linking of CD3 and LFA1 in the presence of a PKC inhibitor (BIM, dotted bars) or an adenylyl cyclase inhibitor (SQ22536, hatched bars). u-PAR mRNA expression was detected by Northern analysis and the films analyzed with a Computing Densitometer. Hybridization of the same blot with a r18s probe was performed to normalize u-PAR mRNA levels. Data are expressed as fold increase over baseline normalized levels in unstimulated cells, and represent the mean $\pm \mathrm{SD}$ of four separate experiments.

the influence of selected pathways of cell activation on uPAR mRNA levels, Northern blot analysis was performed on total RNA extracted from purified T cells, stimulated under various conditions. Unstimulated $\mathrm{T}$ cells displayed low but detectable baseline levels of uPAR mRNA (Fig. $5 A$ ). These were not due to contamination by cells of the mielomonocytic lineage, as the same blot was negative when hybridized with a CD14 probe (not shown). Co-stimulation via CD3 and LFA-1 receptors induced a marked increase in UPAR mRNA levels, which declined after $12 \mathrm{~h}$, while stimulation with anti-CD3 alone was not as efficient in increasing UPAR mRNA. The increases in uPAR mRNA were strongly impaired by treatment with the PKC or the AC inhibitors, BIM and SQ22536 (Fig. 5 B). Activation of $\mathrm{AC}$ with forskolin was cooperative with the effect of PMA also at the mRNA level, resulting in the strongest increase in UPAR mRNA (not shown).

The plasminogen activation system is functional in T lym-
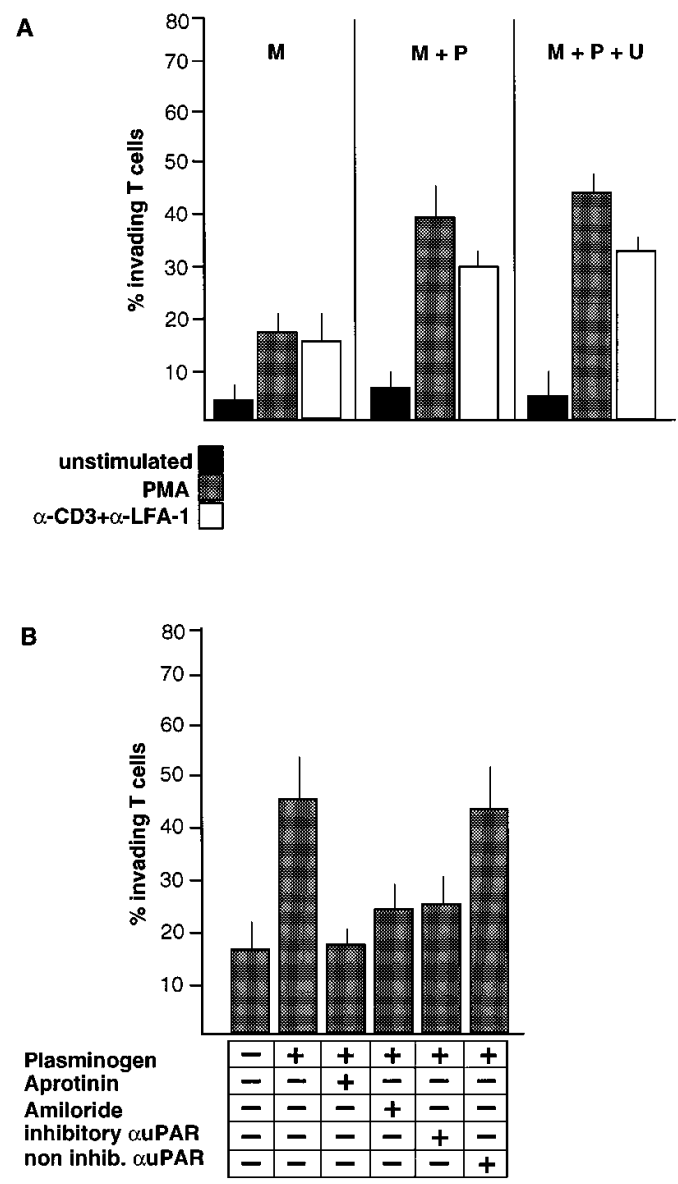

Figure 6. Plasminogen-mediated T cells invasion in vitro. $(A) \mathrm{T}$ cells activated for $72 \mathrm{~h}$ either with PMA ( $100 \mathrm{nM}$, dotted bars) or by crosslinking of CD3 and LFA1 receptors (empty bars) were labeled with ${ }^{51} \mathrm{Cr}$ and tested for their ability to invade through a Matrigel layer, in a double-chamber assay. Invading cells were recovered from the bottom chamber and from the Matrigel layer and are expressed as percentage of cells on the total cell input (mean \pm SD of eight experiments). Unstimulated T cells (black bars) showed consistently low levels of invasion. The assay was also performed in the presence of Matrigel alone $(M)$ or following addition of plasminogen $(100 \mu \mathrm{M}, M+$ $\mathrm{P})$ alone or plasminogen plus urokinase $(0.05 \mathrm{nM}, M+\mathrm{P}+\mathrm{U})$. $(B) \mathrm{T}$ cells activated by crossllinking of CD3 and LFA-1 were tested in the Matrigel invasion assay, in the presence of a plasmin inhibitor (Aprotinin), a urokinase inhibitor (Amiloride) or a blocking or nonblocking antibody against $\mathrm{u}-\mathrm{PAR}$.

phocyte migration. To study whether uPAR plays a role in primary $\mathrm{T}$ cell migration across a basal lamina, purified $\mathrm{T}$ cells were activated by cross-linking of the CD3 and of the LFA-1 receptors, labeled with ${ }^{51} \mathrm{Cr}$ and seeded, in the absence of serum, in the upper compartment of a two-well chamber system. The porous membrane between the two chambers was evenly coated with Matrigel, as an equivalent for subendothelial matrix. Invading $\mathrm{T}$ cells were recovered from the inferior chamber and from the Matrigel layer, after extensive washes to remove loosely attached cells. A sizeable fraction of activated, but not of resting $\mathrm{T}$ cells, was able to actively invade through the Matrigel layer (Fig. 6 A). The fraction of invading T cells was markedly increased by the addition of plasminogen (100 $\mu \mathrm{g} / \mathrm{ml}$; Fig. $6 A)$. Addition of urokinase alone $(0.05 \mathrm{nM}$, not shown) or in combination with plasminogen (Fig. $6 A$ ) did not 

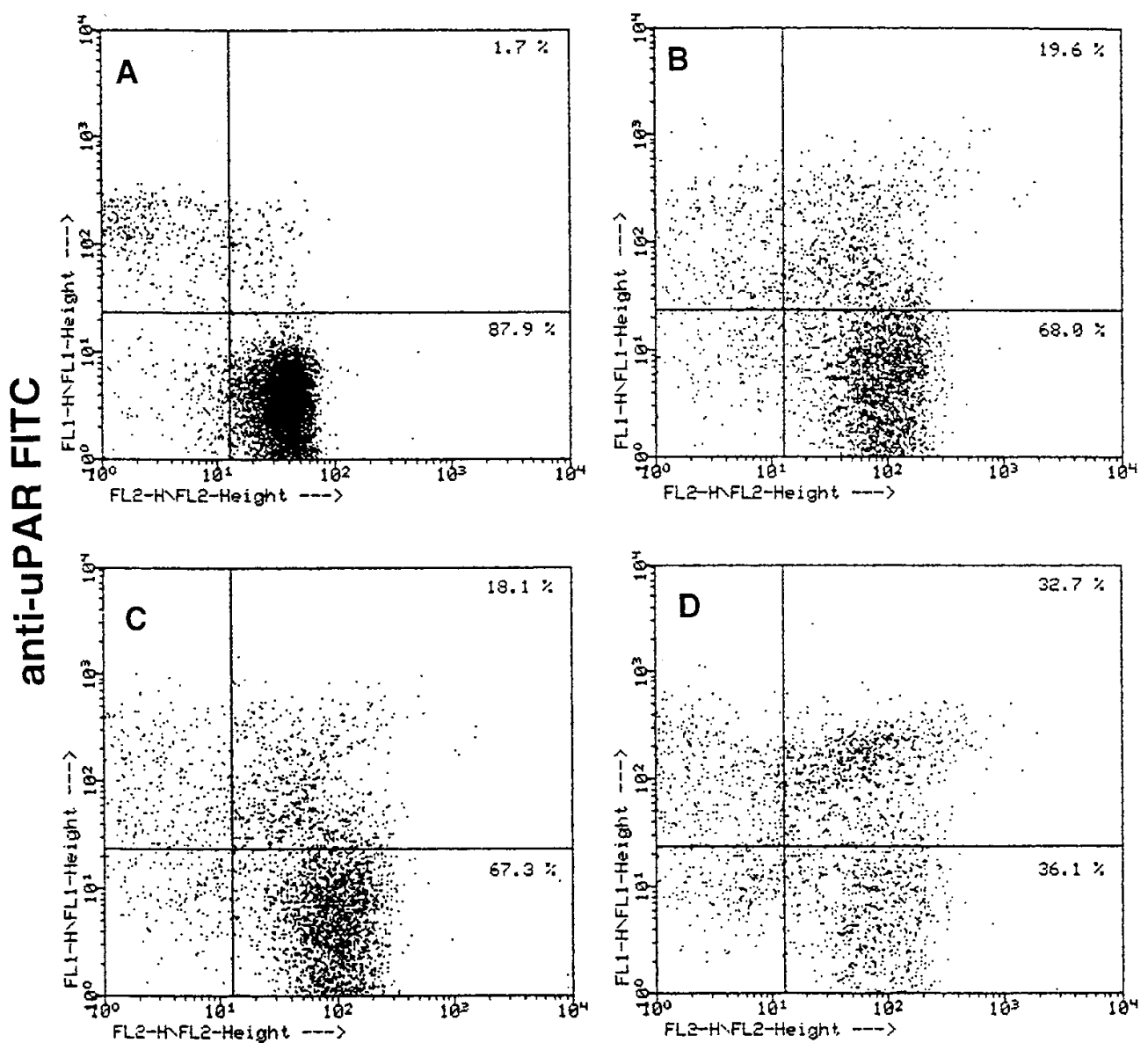

anti-CD3 PE
Figure 7. u-PAR expression by tumor infiltrating lymphocytes ex vivo. Tumor infiltrating lymphocytes were isolated from fresh human tumor specimens by enzymatic digestion and separation on a density gradient. The obtained cell population was analyzed for u-PAR expression by immunofluorescence $(B-D)$. T lymphocytes were identified by expression of the $\mathrm{CD} 3$ receptor. $(A)$ shows $\mathrm{u}$-PAR expression on a B celldepleted mononuclear population from peripheral blood.

Numbers indicate percentage of positive cells on total population analyzed. (FITC) Fluorescein isothiocyanate. $(P E)$ phycoerythrin. affect the levels of T cell migration. Plasminogen-driven invasion was completely abrogated by aprotinin $(10 \mu \mathrm{g} / \mathrm{ml})$, a serine protease inhibitor (Fig. $6 \mathrm{~B}$ ). Strong but partial inhibition was observed with amiloride $(100 \mu \mathrm{g} / \mathrm{ml})$, which blocks uPA activity, or in the presence of an antibody directed against the uPA binding site of uPAR (R3, $5 \mu \mathrm{g} / \mathrm{ml}$ ). A nonblocking anti-uPAR antibody was ineffective (R4, Fig. 6 B).

$u P A R$ expression on tissue-infiltrating T lymphocytes in vivo. To study whether in vivo activated lymphocytes express uPAR, T cells were isolated from fresh human renal and ovarian carcinoma specimens by partial enzymatic digestion, followed by separation on a density gradient. The mononuclear population so obtained was analyzed for UPAR expression by surface immunofluorescence and cytofluorimetric analysis. A variable fraction $(21-47 \%)$ of the tumor infiltrating $\mathrm{CD}^{+} \mathrm{T}$ lymphocytes expressed uPAR on their surface, as detected by cytofluorimetry (Fig. 7, $B-D$ ), while fewer than $2 \%$ of T cells isolated from peripheral blood were $\mathrm{uPAR}^{+}($Fig. $7 A$ ). To confirm this finding in vivo, frozen sections of human tumor samples were analyzed by double immunofluorescence staining. UPAR was detected with a combination of two monoclonal antibodies against nonoverlapping epitopes of the receptor (R2 and R3), followed by detection with a TRITCconjugated secondary antibody. $\mathrm{T}$ cells were identified by staining with an anti-CD3 rabbit polyclonal antiserum, followed by a FITC-conjugated swine anti-rabbit polyclonal. Mononuclear infiltrates were visible in all specimens exam- ined (10 cases); in all cases, $\mathrm{T}$ cells were clearly detected by surface staining with the anti-CD3 antiserum. uPAR expression was detected in most cases, but showed variable degrees of intensity, even among $\mathrm{T}$ cells within the same infiltrate (Fig. 8). In several cases, uPAR positive, CD3 negative cells were also visible, possibly representing macrophages, tumor cells or vascular endothelium lining capillaries or small vessels (Fig. 8). Specificity of the staining was confirmed by omission of the anti-uPAR or the anti-CD3 antibodies, or incubation with an irrelevant control antibody. Cross-reactivity of the secondary antibodies was ruled out by incubating the antiCD3 stained sections with the anti-mouse secondary antibody, and the anti-uPAR stained sections with the anti-rabbit antiserum. Under all these conditions no specific staining was visible (not shown).

\section{Discussion}

During their life span, T lymphocytes need to leave the bloodstream multiple times and extravasate into perivascular tissues to perform immune surveillance and reach the sites of the inflammatory response. $T$ cell transmigration requires an initial interaction with the endothelial lining of the blood vessel, which appears to be mediated mostly by C-type lectins, followed by strengthening of the adhesion, operated by binding of lymphocyte adhesion receptors of the $\beta 1$ or $\beta 2$ integrin subfam- 

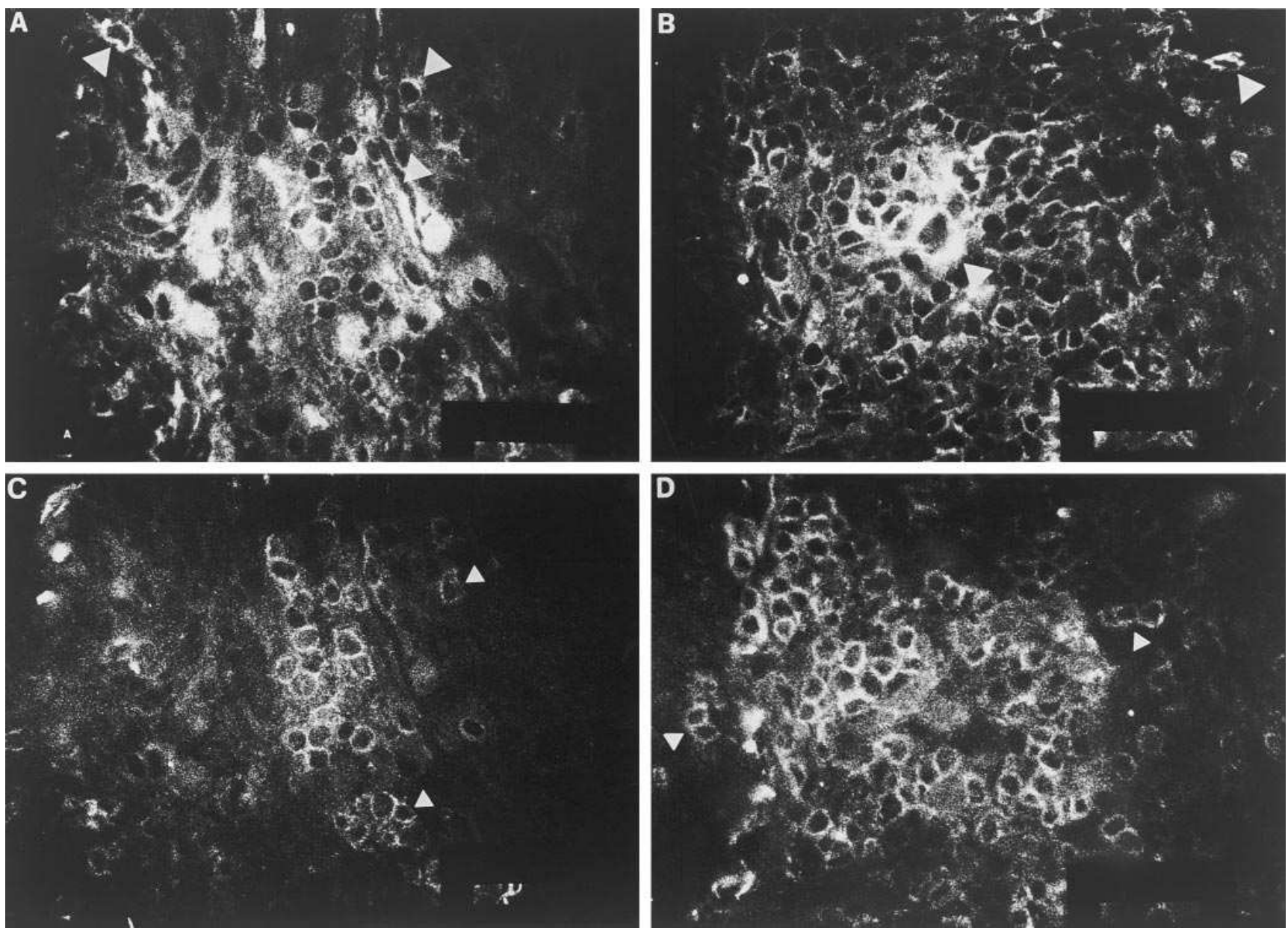

Figure 8. Expression of uPAR by tumor infiltrating T lymphocytes in vivo. 4- $\mu$ m-thick cryosections of primary breast $(A$ and $C)$ or pancreatic $(B$ and $D$ ) carcinomas were stained with a combination anti-uPAR mAbs (R3 and R4) followed by TRITC-conjugated goat anti-mouse IgG antiserum $(A$ and $B)$, and counter-stained with affinity purified rabbit anti-human CD3, followed by FITC-conjugated swine anti-rabbit antiserum $(C$ and $D$ ). Most cellular elements in the selected fields co-express the two markers. Individual $\mathrm{uPAR}^{+} \mathrm{CD}^{-}$and $\mathrm{uPAR}^{-} \mathrm{CD}^{+}$cells are indicated by large and small arrowheads, respectively. Bar, $30 \mu \mathrm{m}$.

ilies to the ligands present on the surface of the endothelial cell $(1,2)$. For integrin-mediated adhesion to occur, the integrin receptors themselves have to undergo a change in their avidity for the ligand, which is brought on by a variety of stimuli, including antigen recognition or chemokine-induced $\mathrm{T}$ cell activation $(3,25,26)$. $\mathrm{T}$ cell integrins may also play a central role in the subsequent transmigration through the basement membrane into the interstitial matrix, though the molecular mechanisms that regulate these phenomena are still poorly defined. Integrins are not only responsible for the attachment to ECM proteins, but are also involved in transducing signals from the extracellular environment, initiating the intracellular cascade of metabolic events necessary for the invasion process (27).

The aim of the present study was to assess the inducibility and the functional role of UPAR in promoting invasion of the extracellular matrix by $\mathrm{T}$ lymphocytes, activated by stimuli which are likely to be associated with the interaction between $\mathrm{T}$ cells and endothelial cells or ECM, that occurs during the transmigration process. Our results show that co-clustering of CD3 and of the integrin $\alpha \mathrm{L} \beta 2$ (LFA-1) with specific antibodies is a very efficient stimulus for high affinity UPAR induction on T cells, while cross-linking of the antigen receptor complex (CD3) alone induces low levels of uPAR. The increased cell surface expression is paralleled by an increase in uPAR mRNA, suggesting the existence of transcriptional and/or posttranscriptional mechanisms for the control of uPAR levels by membrane receptors involved in cell-cell and cell-extracellular matrix adhesion. Other integrin receptors present on lymphocytes, such as $\alpha 4 \beta 1$ (VLA-4) or $\alpha 5 \beta 1$ (VLA-5), were also capable of synergizing with signalling through the CD3 complex in inducing uPAR. Although $\beta 1$ integrin costimulation did not induce uPAR expression levels higher than those obtained by co-clustering of CD3 and $\beta 2$ integrins on T cells, it delayed significantly the disappearance of the receptor in stimulated cells (Fig. 2). These data are in agreement with the studies showing that the engagement of integrins is capable of modifying gene expression, by acting both at the transcriptional and posttranscriptional level. Interestingly, among the genes induced upon stimulation of integrin receptors are several proteases: stimulation of $\alpha 5 \beta 1$ on fibroblasts induces stromelysin and collagenase (28), engagement of $\alpha \mathrm{V} \beta 3$ stimulates expression of a 72-kD gelatinase in a melanoma cell line (29), antibodies against $\alpha 3 \beta 1$ induce a $92-\mathrm{kD}$ type IV collagenase in keratinocytes (30). In T lymphocytes, adhesion to VCAM1 (presumably through its counter receptor $\alpha 4 \beta 1$ ) induces secretion of the $72-\mathrm{kD}$ gelatinase, an event that was 
shown to facilitate $\mathrm{T}$ cell invasion through a three-dimensional matrix (31).

The intracellular pathways that mediate integrin signaling are largely unknown. We have analyzed the intracellular messengers responsible for UPAR induction, with the use of specific modulators of known metabolic pathways. In agreement with data in the literature (14), our experiments confirm that activation of PKC by phorbol esters (PMA) is sufficient to induce UPAR expression. A selective PKC inhibitor (BIM) abolished completely not only uPAR induction by PMA, but also uPAR expression following CD3 stimulation, providing evidence for a central role for PKC activation in UPAR induction through CD3. Phosphatidylinositol hydrolysis and production of 1,2-diacylglycerol (DAG) is an early event following $\mathrm{T}$ cell antigen receptor stimulation (20). The activation of PKC by $\mathrm{DAG}$ is an important event in inducing the synthesis of $\mathrm{T}$ cell nuclear transcription factor (NF-AT) and regulating the activity of transcription factors of the AP-1 and NF-kB family (3234). Though the transcription factors possibly involved in UPAR induction in T cells have not been characterized, it is interesting to note the existence, in the UPAR promoter, of consensus binding sites for AP-1 and NF-kB factors (35).

It has been reported that a cAMP-dependent pathway mediates UPAR expression in cultured endothelial cells (36). Since cross-linking of the CD3 receptor on lymphocytes increases the intracellular concentration of cAMP and the simultaneous clustering of CD3 and LFA-1 is even a more potent agonist in stimulating cAMP increase (24), we tested whether variations in intracellular cAMP contributed to UPAR induction also in T lymphocytes. The increased cAMP concentration induced by direct activation of adenylyl cyclase (AC) by FSK synergized with PKC activation in inducing UPAR expression, though treatment with FSK alone had no effect on UPAR induction in T cells (not shown), in contrast with what described for endothelial cells. Addition of a specific AC inhibitor (SQ22536) abolished the synergistic effect of FSK treatment, suggesting that the two pathways for uPAR induction may be at least partially independent. The AC inhibitor also abolished uPAR expression induced in T cells by crosslinking of CD3 alone and greatly reduced the effect of CD3 and LFA-1 co-clustering, suggesting that an increase in cAMP is important in signalling through this pathway.

UPAR expressed on activated T cells appears to be functional in promoting $\mathrm{T}$ cell migration: invasion of $\mathrm{T}$ cells in vitro through a basement membrane equivalent (Matrigel) was enhanced by the addition of plasminogen, the substrate for urokinase, and impaired by treatment with a uPA inhibitor, amiloride (37), or by addition to the system of a blocking antibody against uPAR. Treatment with a serine protease inhibitor, aprotinin, also blocked plasminogen-dependent migration. A small fraction of activated T cells $(16 \pm 3 \%)$ migrated also in the absence of added plasminogen: this fraction could not be reduced by addition of aprotinin to the system (not shown), suggesting that other proteolytic systems are also likely to play a role in lymphocyte migration. Activated T cells are known to express, in addition to the metalloproteinases ( 72 and $92 \mathrm{kD}$ ), active against collagen types IV and $\mathrm{V}$, an array of enzymes potentially active against components of the ECM, such as heparanase, an endoglycosidase which degrades proteoglycans of the subendothelial basement membrane, cathepsin D and elastase $(31,38-41)$. Though the role of these proteases in lymphocyte biology has not been established, the outcome of $\mathrm{T}$ cell migration is possibly dictated by the concerted action of all these degradative pathways. Interestingly, addition of urokinase had no influence on the extent of lymphocyte migration. This could be due to the fact that anti-CD3 plus antiLFA-1-stimulated, but not resting, $\mathrm{T}$ cells secrete small amounts of urokinase, as demonstrated by the activity of $\mathrm{T}$ cell supernatants in a zymography assay (not shown). Consistent with this result, we observed low but detectable levels of uPA mRNA in activated $\mathrm{T}$ cells by Northern blot analysis (not shown).

To understand the functional relevance of the expression of UPAR by T lymphocytes in vivo, we asked whether infiltrating $\mathrm{T}$ cells in human tissues expressed UPAR on their plasma membrane. Immunofluorescence analysis of lymphocyte infiltrates in tumor sections confirmed that a significant fraction of $T$ cells present in the context of the extravascular tissues expressed UPAR on their surface, though with different levels of intensity. These data are in agreement with the analysis of infiltrating T lymphocytes, isolated ex vivo from human tumors, which demonstrated the presence of a variable fraction of uPAR positive, CD3 positive cells. The previously undescribed presence of UPAR on $\mathrm{T}$ lymphocytes in vivo is in agreement with a possible role for plasminogen activation in processes that require $\mathrm{T}$ cell migration.

Many reports have underlined the importance of the uPA system in promoting experimental tumor metastasis in vitro and in vivo in animal models, and have suggested the possibility of interfering with the metastatic process by inhibiting uPA activity (42-48). uPA bound to the cell surface of the T cell leukemia line Jurkat has been shown to facilitate its invasion into fibrin matrices in vitro (49). Studies focused on the involvement of the plasminogen activation system in primary human T leukemias and lymphomas will be necessary to attest the importance of UPA in tumor T cell invasion of solid tissues. Finally, recent evidence indicates that UPAR is part of a molecular complex capable of mediating adhesion to matrix components (50) and transmembrane signalling (15), thus suggesting the existence of strong co-operative interactions amongst receptors involved in migration, adhesion, and matrix degradation. Our data are consistent with the notion that the stromal component participates in establishing the "invasive phenotype" of tumors. It has been shown that in human colon cancer that uPA is produced by stromal fibroblasts, whereas uPAR is present on tumor cells (51). In breast tumors, in addition to cancer cells, tumor-infiltrating macrophages and endothelial cells express uPAR $(52,53)$. Our results show that uPAR-positive $\mathrm{T}$ lymphocytes are also present in human tumors and may participate in the establishment of the overall invasive phenotype. Confirmation in this context of the pathogenic role of uPA activity, together with the design of selective inhibitors, might be useful for the development of novel therapeutic approaches to T cell-mediated diseases.

\section{Acknowledgments}

We gratefully acknowledge F. Sanvito for help and advice with the immunohistochemical studies.

This work is supported in part by grants from the Associazione Italiana Ricerca sul Cancro (F. Blasi and R. Pardi), the European Community Biomedicine and Health Program grant BMH4CT950875 (R. Pardi), the AIDS Fund of the Italian Ministry of Health (F. Blasi) and the National Institutes of Health grant HL43331 (J.R. Bender). 
J.R. Bender is a Raymond and Beverly Sackler Foundation Inc. Scholar.

\section{References}

1. Picker, J.L., and E.C. Butcher. 1992. Physiological and molecular mechanisms of lymphocyte homing. Annu. Rev. Immunol. 10:561-592.

2. Springer, T.A. 1994. Traffic signals for lymphocyte recirculation and leukocyte emigration: the multistep paradigm. Cell. 76:301-314.

3. Dustin, L.M., and T.A. Springer. 1989. T cell receptor cross-linking transiently stimulates adhesiveness through LFA-1. Nature (Lond.). 341:619-624.

4. Vassalli, J.D., A.P. Sappino, and D. Belin. 1991. The plasminogen activator/plasmin system. J. Clin. Invest. 88:1067-1072.

5. Conese, M., and F. Blasi. 1995. The urokinase/urokinase receptor system and cancer invasion. Bailliere's Clin. Haematology. 8:365-389.

6. Kramer, M.D., B. Schaefer, and J. Reinartz. 1995. Plasminogen activation by human keratinocytes: molecular pathways and cell-biological consequences. Biol. Chem. Hoppe-Seyler. 376:131-141.

7. Vassalli, J.-D., D. Baccino, and D. Belin. 1985. A cellular binding site for the $M_{\mathrm{r}} 55,000$ form of the human plasminogen activator urokinase. J. Cell Biol. 100:86-92.

8. Stoppelli, M.P., A. Corti, A. Soffientini, G. Cassani, F. Blasi, and R.K. Assoian. 1985. Differentiation-enhanced binding of the amino-terminal fragment of human urokinase plasminogen activator to a specific receptor on U937 monocytes. Proc. Natl. Acad. Sci. USA. 82:4939-4943.

9. Roldan, A.L., M.V. Cubellis, M.T. Masucci, N. Behrendt, L.R. Lund, K. Danø, E. Appella, and F. Blasi. 1990. Cloning and expression of the receptor for human urokinase plasminogen activator, a central molecule in cell surface, plasmin dependent proteolysis. EMBO (Eur. Mol. Biol. Organ.) J. 9:467-474.

10. Estreicher, A., J. Mühlhauser, J.-L. Carpentier, L. Orci, and J.-D. Vassalli. 1990. The receptor for urokinase type plasminogen activator polarizes expression of the protease to the leading edge of migrating monocytes and promotes degradation of enzyme inhibitor complexes. J. Cell Biol. 111:783-792.

11. Min, H.Y., R. Semnani, I.F. Mizukami, K. Watt, R.F.I. Todd, and D.Y. Liu. 1992. cDNA for Mo3, a monocyte activation antigen, encodes the human receptor for urokinase plasminogen activator. J. Immunol. 148:3632-3642.

12. Miles, L.A., and E.F. Plow. 1987. Receptor mediated binding of the fibrinolytic components, plasminogen and urokinase, to peripheral blood cells. Thromb. Haemost. 58:936-942.

13. Nykjaer, A., C.M. Petersen, B. Møller, P.A. Andreasen, and J. Glieman. 1992. Identification and characterization of urokinase receptors in natural killer cells and in T-cell-derived lymphokine activated killer cells. FEBS Lett. 300:13-17.

14. Nykjaer, A., B. Møller, R.F.I. Todd, T. Christensen, P.A. Andreasen, J. Gliemann, and C.M. Petersen. 1994. Urokinase Receptor. An activation antigen in human T lymphocytes. J. Immunol. 152:505-516.

15. Resnati, M., M. Guttinger, S. Valcamonica, N. Sidenius, F. Blasi, and F. Fazioli. 1996. Proteolytic cleavage of the urokinase receptor substitutes for the agonist-induced chemotactic effect. EMBO (Eur. Mol. Biol. Organ.) J. 15:1572-1582.

16. Rønne, E., N. Behrendt, V. Ellis, M. Ploug, K. Dan $\varnothing$, and G. HøyerHansen. 1991. Cell-induced potentiation of the plasminogen activation system is abolished by a monoclonal antibody that recognizes the $\mathrm{NH}_{2}$-terminal domain of the urokinase receptor. FEBS Lett. 288:233-236.

17. Wysocki, L.J., and V.L. Sato. 1978. Panning for lymphocytes. A method for cell separation. Proc. Natl. Acad. Sci. USA. 75:2844-2848.

18. Appella, E., Robinson, E.A., Ullrich, S.J., Stoppelli, M.P., Corti, A., Cassani, G., and F. Blasi. 1987. The receptor binding sequence of urokinase. A biological function for the growth factor module of proteases. J. Biol. Chem. 262:4437-4440.

19. Blasi, F. Surface receptors for urokinase plasminogen activators. 1988. Fibrinolysis. 2:73-84.

20. Imboden, J.B., and J.D. Stobo. 1985. Transmembrane signaling by the $T$ cell antigen receptor: perturbation of the T3-antigen receptor complex generates inositol phosphates and releases calcium ions from intracellular stores. $J$. Exp. Med. 161:446-456.

21. Szamel, M., and K. Resch. 1995. T-cell antigen receptor-induced signal transduction pathways. Activation and function of protein kinases $\mathrm{C}$ in $\mathrm{T}$ lymphocytes. Eur. J. Biochem. 228:1-15.

22. Pardi, R., J.R. Bender, C. Dettori, F. Giannazza, and E.G. Engleman. 1989. Heterogeneous distribution and transmembrane signaling properties of lymphocyte function-associated antigen (LFA-1) in human lymphocyte subsets. J. Immunol. 143:3157-3166.

23. Kanner, S.B., L.S. Grosmaire, J.A. Ledbetter, and N.K. Damle. 1993. $\beta 2$-integrin LFA-1 signaling through phospholipase C- $\gamma 1$ activation. Proc. Natl. Acad. Sci. USA. 90:7099-7103.

24. Rovere, P., L. Inverardi, J.R. Bender, and R. Pardi. 1996. Feedback modulation of ligand-engaged $\alpha \mathrm{L} / \beta 2$ leukocyte integrin (LFA-1) by cyclic AMP-dependent protein kinase. J. Immunol. 156:2273-2279.

25. Pardi, R., L. Inverardi, C. Rugarli, and J.R. Bender. 1992. Antigenreceptor complex stimulation triggers protein kinase C-dependent CD11a/ CD18-cytoskeleton association in T Lymphocytes. J. Cell Biol. 116:1211-1220.

26. Imhof, B.A., and D. Dunon. 1995. Leukocyte migration and adhesion.
Adv. Immunol. 58:345-416.

27. Rosales, C., and R.L. Juliano. 1995. Signal transduction by cell adhesion receptors in leukocytes. J. Leuk. Biol. 57:189-198.

28. Werb, Z., P.M. Tremble, O. Behrendtsen, E. Crowley, and C.H. Damsky. 1989. Signal transduction through the fibronectin receptor induces collagenase and stromelysin gene expression. J. Cell Biol. 109:877-889.

29. Seftor, R.E., E.A. Seftor, W.G. Stetler-Stevenson, and M.J. Hendrix. 1993. The $72 \mathrm{kDa}$ type IV collagenase is modulated via differential expression of alpha v beta 3 and alpha 5 beta 1 integrins during human melanoma cell invasion. Cancer Res. 53:3411-3415.

30. Larjava, H., J.G. Lyons, T. Salo, M. Makela, L. Koivisto, H. BirkedalHansen, S.K. Akiyama, and J. Heino. 1993. Anti-integrin antibodies induce type IV collagenase expression in keratinocytes. J. Cell. Physiol. 157:190-200.

31. Romanic, A.M., and J.A. Madri. 1994. The induction of 72-kD gelatinase in T cells upon adhesion to endothelial cells is VCAM-1 dependent. J. Cell Biol. 125:1165-1178.

32. Clipstone, N.A., and G.R. Crabtree. 1993. Calcineurin is a key signaling enzyme in T lymphocyte activation and the target of the immunosuppressive drugs cyclosporin A and FK506. Ann. NY Acad. Sci. 696:20-30.

33. Siebenlist, U., G. Franzoso, and K. Brown. 1994. Structure, regulation and function of NF-kB. Annu. Rev. Cell Biol. 10:405-455.

34. Genot, E.M., P.J. Parker, and D.A. Cantrell. 1995. Analysis of the role of protein kinases C-alpha, -epsilon and -zeta in T cell activation. J. Cell Biol. 270:9833-9839.

35. Soravia, E., A. Grebe, P. De Luca, K. Helin, T.T. Suh, J.L. Degen, and F. Blasi. 1995. A conserved TATA-less proximal promoter drives basal transcription from the urokinase-type plasminogen activator receptor gene. Blood. 86:624-635.

36. Langer, D.J., A. Kuo, K. Kariko, M. Ahuja, B.D. Klugherz, K.M. Ivanics, J.A. Hoxie, W.V. Williams, B.T. Liang, D.B. Cines, and E.S. Barnathan. 1993. Regulation of the endothelial cell urokinase-type plasminogen activator receptor. Evidence for cyclic AMP-dependent and protein kinase C-dependent pathways. Circ. Res. 72:330-340.

37. Vassalli, J.D., and D. Belin. 1987. Amiloride selectively inhibits the urokinase-type plasminogen activator. FEBS Lett. 214:187-191.

38. Leppert, D., E. Waubant, R. Galardy, N.W. Bunnet, and S.L. Hauser. 1995. T cell gelatinase mediate basement membrane transmigration in vitro. $J$. Immunol. 154:4379-4389.

39. Fulton, R.J., and D.A. Hart. 1980. Detection and partial characterization of lymphoid cell surface proteases. Cell. Immunol. 55:394-405.

40. Bristow, C.L. L.K. Lyford, D.P. Stevens, and P.M. Flood. 1991. Elastase is a constituent product of T-cells. Biochem. Biophys. Res. Commun. 181:232-239.

41. Vlodavsky, I., A. Eldor, H.-F. A., Y. Matzner, R. Ishai-Michaeli, O. Lider, Y. Naparstek, I.R. Cohen, and Z. Fucks. 1992. Expression of heparanase by platelets and circulating cells of the immune system: possible involvement in diapedesis and extravasation. Invasion Metastasis. 12:112-127.

42. Ossowski, L., and E. Reich. 1983. Antibodies to plasminogen activator inhibit human tumor metastasis. Cell. 35:611-619.

43. Mignatti, P., E. Robbins, and D.B. Rifkin. 1986. Tumor invasion through the human amniotic membrane: requirement for a proteinase cascade. Cell. 47:487-498.

44. Ossowski, L. 1988. In vivo invasion of modified chorioallantoic membrane by tumor cells: the role of cell surface-bound urokinase. J. Cell Biol. 107: 2437-2445.

45. Hearing, V.J., L.W. Law, A. Corti, E. Appella, and F. Blasi. 1988. Modulation of metastatic potential by cell surface urokinase of murine melanoma cells. Cancer Res. 48:1270-1278.

46. Ossowski, L., H. Russo-Payne, and E.L. Wilson. 1991. Inhibition of urokinase-type plasminogen activator by antibodies: The effect on dissemination of a human tumor in the nude mouse. Cancer Res. 51:274-281.

47. Crowley, C.W., R.L. Cohen, B.K. Lucas, G. Liu, M.A. Shuman, and A.D. Levinson. 1993. Prevention of metastasis by inhibition of the urokinase receptor. Proc. Natl. Acad. Sci. USA. 90:5021-5025.

48. Kobayashi, H., J. Gotoh, M. Fujie, H. Shinohara, N. Moniwa, and T. Terao. 1994. Inhibition of metastasis of Lewis lung carcinoma by a synthetic peptide within the growth factor-like domain of urokinase in the experimental and spontaneous matastasis model. Int. J. Cancer. 57:723-733.

49. Kramer, M.D., H. Spring, R. Todd, and U. Vettel. 1994. Urokinase-type plasminogen activator enhances invasion of human $\mathrm{T}$ cells (Jurkat) into a fibrin matrix. J. Leuk. Biol. 56:110-116.

50. Waltz, D.A., and H.A. Chapman. 1994. Reversible cellular adhesion to vitronectin linked to urokinase receptor occupancy. J. Biol. Chem 269:14746-14750.

51. Pyke, C., P. Kristensen, E. Ralfkiaer, J. Grøndahl-Hansen, J. Eriksen, F. Blasi, and K. Danø. 1991. Urokinase-type plasminogen activator is expressed in stromal cells and its receptor in cancer cells at invasive foci in human colon adenocarcinomas. Am. J. Path. 138:1059-1067.

52. Pyke, C., N. Graem, E. Ralfkiaer, E. Rønne, G. Høyer-Hansen, N. Brünner, and K. Danø. 1993. Receptor for urokinase is present in tumor-associated macrophages in ductal breast carcinoma. Cancer Res. 53:1911-1915.

53. Bianchi, E., R.L. Cohen, A.T. Thor, R.F.I. Todd, I.F. Mizukami, D.A Lawrence, B.M. Ljung, M.A. Shuman, and H.S. Smith. 1994. The urokinase receptor is expressed in invasive breast cancer but not in normal breast tissue. Cancer Res. 54:861-866. 